\title{
Impact of Behavioral and Medical Problems on Physical Activity in Male Egyptian Young Adults
}

\author{
Sameh Sh. Zaytoun', Raouf M. Afifi' ${ }^{*}$, Amani Qulali'2, Hesham A. K. Ayoub ${ }^{3}$ \\ ${ }^{1}$ Department of Community Medicine, South Valley University, Qena, Egypt \\ ${ }^{2}$ Community Health Institute, International Management-Health Services Inc., Indianapolis, Indiana, USA \\ ${ }^{3}$ Department of Internal Medicine, Military Medical Academy, Cairo, Egypt \\ Email: *raoufafifi@hotmail.com
}

Received 4 July 2015; accepted 3 November 2015; published 6 November 2015

Copyright (C) 2015 by authors and Scientific Research Publishing Inc.

This work is licensed under the Creative Commons Attribution International License (CC BY).

http://creativecommons.org/licenses/by/4.0/

(c) (i) Open Access

\begin{abstract}
Physical inactivity is generally accepted as one of the most serious health risk behaviors of young adults contributing to poorer health outcome. This study aimed at determining the impacts of behavioral and medical problems on physical activity (PA) among the Egyptian youth. In this study, 500 Egyptian men aged 18 - 30 years old attending for medical examination in Qena University Outpatient department between March 2013 and March 2014 were surveyed; risk factors for physical inactivity were analyzed. Significantly, $58.0 \%$ of smokers demonstrated the tendency to physical inactivity; only $0.8 \%$ did vigorous $P A[X(\mathrm{df}=2)=15.53, p<0.001]$. Most of those with history of drug abuse and all alcoholics reported low PA tendency $\left[X^{2}(\mathrm{df}=2)=13.96, p<0.001\right.$, Fisher's exact $=6.3, p=0.045$, respectively]. As much as $87.1 \%$ of the obese had mild PA, too $\left[X^{2}\right.$ (df $=2)=16.62, p<0.001]$. Heart disease was also associated with a tendency of physical inactivity $\left[X^{2}(\mathrm{df}=2)=15.6, p<0.001\right]$. Most anemics $(68.9 \%)$ reported mild PA and $31 \%$ of them reported having moderate PA $\left[X^{2}(\mathrm{df}=2)=8.22, p=0.027\right]$. Both, hepatitis B virus (HBV)- and hepatitis $C$ virus (HCV)-infection, and diabetes mellitus (DM) were not risk for physical inactivity. The present work provides that PA diminishes with some chronic illnesses and behavioral derangements, e.g., drug abuse and smoking. Interestingly, HBV, HCV infections and DM are not among risks for physical inactivity.
\end{abstract}

\section{Keywords}

Physical Inactivity, Young Males, Risks, Smoking, Drug Abuse, Egypt

\footnotetext{
*Corresponding author.
}

How to cite this paper: Zaytoun, S. Sh., Afifi, R. M., Qulali, A., \& Ayoub, H. A. K. (2015). Impact of Behavioral and Medical Problems on Physical Activity in Male Egyptian Young Adults. Advances in Physical Education, 5, 234-244. 


\section{Introduction}

Physical inactivity is generally accepted as one of the most serious health risk behaviors of young adults contributing to poorer health, high risk of some chronic diseases and higher rates of premature mortality. Physical inactivity denotes a level of physical activity less than that needed to maintain good health (Kolbe, 1990). Physical activity is defined as "bodily movements produced by skeletal muscles that substantially increase the energy expenditure". Exercise, a type of physical activity, is defined as "a planned, structured, and repetitive bodily movement done to improve or maintain one or more components of physical fitness" (Pate et al., 1995). Physical fitness is considered as the level that relates to performance of the physical activity. It has three essential components: a) cardiopulmonary endurance; b) muscular strength and endurance; c) flexibility (bending, stretching and joint movement) (Blair et al., 1989). The prevalence of physical inactivity varies by gender, age ethnicity, health status as well as the geographic region. The problem of inactivity has been found more pronounced in females than males especially those with lower income and less education, as well as the elder people are more inactive than the young ones. Moreover, changes in physical exertion associated with occupation have declined markedly in this century (Salmon, 2000). Physical inactivity, together with a sedentary lifestyle, may be attributed to a multitude of etiologic factors (Moore et al., 1991) falling under three main categories: a) behavioral factors, where the behavior of physical inactivity or even PA is usually constructed early and influenced by the social environmental surroundings, such as the family, school, peers; b) lifestyle, which involves a way of living without any regular PA or leisure time exercises, e.g., as in sedentary occupations and home-ridden states; c) chronic morbidity, such that chronic illness and disability can have a great role in development of physical inactivity and initiate a vicious circle where the more inactivity, the worse the morbidity e.g. obesity and diabetes mellitus.

Assessment and benefits of physical activity: There is no standard measure for assessment of physical activity. However, it is often classified as (Washburn \& Montoye, 1986) a) vigorous activity, which is defined as any activity causing sweating and hard breathing for at least 20 minutes on 3 or more days of the week; b) moderate activity which is defined as activities such as walking or bicycling lasting for at least 30 minutes on 5 or more days of the week; and c) mild activity, which includes any activities for less than 30 minutes for 4 days or less per week. The health benefits of regular PA are numerous, and all may well be mitigated by being engaged into a physical inactivity and sedentary life state. For instance, it has been found that physical inactivity increases the risk for the development of many chronic diseases such as coronary heart disease (CHD), DM and hypertension, as well as premature mortality. On the one hand, regular PA has been met with reduction of the risk of cardiovascular morbidity and mortality in general of CHD in particular. It is estimated that $37 \%$ of CHDs can be attributed to physical inactivity. In addition, physical inactivity may be responsible for up to a threefold increase in the risk of stroke (Fletcher et al., 1992). Prevention or delaying the onset of high blood pressure, and reducing blood pressure in people with hypertension have also been associated with PA. Largely, regular endurance exercise lowers both systolic- and diastolic-blood pressure by about $10 \mathrm{mmHg}$ each in those with mild hypertension (both sexes). Otherwise, people with normal blood pressure may enjoy $5 \mathrm{~mm}$ systolic and 3mm diastolic loss in blood pressure on average to engagement into regular exercise (Raitakari et al., 1994). Likewise, PA helps control body weight and lowering the risk of obesity through increasing energy expenditure and enhancing "energy balance". In addition, PA favorably affects body fat distribution and leads to retention of lean body mass (Klesges et al., 1990). Physical activity also has an important role in lowering the risk of developing type-2 diabetes through increasing the tissues' sensitivity to insulin (Klesges et al., 1990). The risk of some cancers may also be minimized in association with PA. The estimates vary with this regard, but, e.g., it has been suggested that regular PA reduces the risk of cancer colon by around 40\%. Other physiological and also psychological benefits of PA are numerous. For instance, PA helps building and maintaining healthy bones, muscles and joints, and making people with chronic disabling conditions improve their stamina. It has also been found that PA helps in the management of painful conditions, such as back pain or knee pain (Klesges et al., 1990). Reduced risk of depression and other positive benefits for mental health including reduced anxiety, enhanced mood and self esteem, all have been linked to PA. Ultimately, PA appears to improve health-related quality of life (HRQOL) by enhancing the psychological well-being and controlling those risky behaviors such as smoking, drug abuse, unhealthy diet and violence (CDC, 1997). Physical activity needs not to be strenuous to be beneficial. Moderate amounts of physical activity are recommended for all ages for at least 30 minutes daily which will be enough to bring the desired health effect. However, by increasing the level of activity, the benefits will also increase (Ferraro \& Holland, 2002). 


\section{Methods}

The study was undertaken in Qena University Hospital (QUH) in Southern Egypt. The hospital is a teaching health institution affiliated to the Qena Medical Center (QMC). The center receives referrals from the affiliated health institutions in Qena, Luxor and Red Sea governorates. A total number of 500 men, 18 - 30 years of age men were randomly selected between March 2013 and March 2014, using systematic random sampling technique. The study sample frame included outpatient appointment individuals, pre-employment check up referrals, or subjects attending for preventive services, such as screening or regular follow up and household or work contacts of infectious disease patients. The study subjects were informed that their consent to participate in the study is considered a permission to access their medical records, if available, as necessary by these investigators for research purpose. Un-insured persons or those on private plans were offered a free consultation and follow up for their current complaint, if any. Refusal to give a permission to own medical information was considered an apology to participate, and hence exclusion from the study. Otherwise, necessary approvals from the institutional review board (IRB) of QMC have been granted. Selected participants were first informed of the study's aim, assuring them of the confidentiality of their personal information, and that only grouped data would be displayed for research purpose. Verbal acceptance to be among the study group was considered an informed consent to take part in this research. Nonetheless, participants were informed that their participation is voluntary, and that they could opt to withdraw from the study at anytime without giving reasons and that such withdrawal cannot affect the healthcare benefits to which they are entitled. The study sample was randomly selected to represent the relative population size of the three participating Southern governorates (Qena: 2,801,110, Luxor: 1,064,026, Red Sea: 321,079 populations) (CAPMS, 2012).

Two major approaches were adopted to collect study data: a validated predesigned questionnaire instrument and a standardized clinical interview, including medical record review. The questionnaire consists of 82 items in five scales: a) Demographic and socioeconomic criteria, e.g. age, occupational history, including current and previous work/profession, role at work, residence, and marital status. The educational and income levels were measured as per Fahmy and El-Sherbini “socio-economic scoring system of Egyptian population” (Fahmy \& El Sherbini, 1983). Educationally, our study population could be divided into two groups: i) those with a lower educational level (less than nine years of essential education, including those who had finished preparatory school, and those who can read and write or only completed primary school, as well as illiterate people, and might be referred to in this research as $\leq \mathrm{K}-9$ ), and ii) those with more than nine years of education, including those who had completed secondary school or equivalent, and university education or above, and might be referred to as >K-9. b) Lifestyle and risk factors, e.g., special habits, including tobacco use, alcohol intake, and drug dependence. Smoking was categorized into three levels based on the number of smoked cigarettes per day (cigs/d): light ( 1 - 10 cigs/d), moderate (11 - 20 cigs/d), heavy (21 - 39 cigs/d), very heavy ( $\geq 40$ cigs/d) (Bhat et al., 2008). Items on substance abuse were structured and phased in the context of "drug dependence" as per the WHO definition (JUNP-AIDS/HIV, 2004). Otherwise, a person was aid to be a smoker of he was doing so on daily basis (Bhat et al., 2008). Included in the questionnaires, too, was a list of drugs and substances as per the ICD-10 classification of dependence producing drugs, (Siegel et al., 2000) (including alcohol, opioids, cannabinoids (hashish or bango), sedatives or hypnotics, cocaine, other stimulants, hallucinogens, volatile solvents and multiple drugs. Examples of trade names of each drug group popular in the Egyptian drug addiction black market for Egyptian drug consumers were provided (Zaytoun et al., 2015). (Often, the term “addict” or "drug addict” might be used in lieu of the term "drug dependent” in this work, because the word "addiction" or often "narcotics addiction" is the exact word commonly used by most Egyptians to describe drug abuse habitual states we tend to identify in this research). c) Health status, including obesity, DM; chronic heart disease, chest disease, including BA, neurological problems, e.g., epilepsy; as well as HBV and HBV infections. [(i) Obesity means a person's weight and height coinciding with a body mass index (BMI) $30 \mathrm{~kg} / \mathrm{m}^{2}$ or above. (ii) A subject is said to be diabetic (type 1or type 2 if there was a reported history of DM and a medical diagnosis, as extracted from his medical record based on the presence of criteria of a laboratory diagnosis of DM (Afifi \& Omar, 2012)]. Also, the presence of a history of receiving oral hypoglycemic and or insulin therapy, as well as symptoms of hyperglycemia or hyperglycemic crisis in the pertinent questionnaire response, especially when random plasma glucose (RPG) had been warranted thorough medical search to confirm the presence of DM (ADA, 2011). (iii) A subject is said to have coronary heart disease (CHD), as the main focus for chronic heart disease in this study, is that who fulfill the definition of CHD of the National Heart, Lung, and Blood Institute (NHLBI, 2013; AHA, 
2013). (iv) Bronchial asthma, as the main focus for chronic respiratory illness as in this research, would be confirmed in accordance with the definition of BA set by the Global Initiative for Asthma, 2011 (GSAP, 2011). (v) Viral hepatitis: HBV infection was defined and diagnosed in this study based on the referenced serological and molecular criteria for chronic HBV infection diagnosis (CDC, 2014). (Those with previous history of HBV infection who had come to complete clearance of HBV load were not considered as having hepatitis disease). Also, HCV infection was defined and diagnosed in this study as per the referenced serological and molecular criteria for chronic HCV infection. (Those with history of HCV infection whose blood was cleared from HCV load were not labeled as having chronic HCV disease). (vi) Epilepsy and seizure disorders patients were labeled as such, whether they were controlled or uncontrolled. Due to the wide scope and varying degrees of seizure disorders, determining the presence of epilepsy and type of seizures was based on the patient's medical history and current medications as drawn during the clinical interview, complete physical and neurological examination, alongside with reviewing the participants' medical records and diagnostic and follow up investigations, such as electroencephalogram (EEG), magnetic resonance imaging (MRI), and pertinent laboratory tests, as well as having input of people who have witnessed the patient's seizures, especially if there is a loss of consciousness and meeting with the treating physician for confirming the diagnosis; all were attempted (EHC, 2014).

The outcome variable: This work was principally undertaken to study the pattern of physical inactivity vs. physical activity in the Egyptian young men generation; how such pattern might be affected by a myriad of conditions, e.g., impaired health status, young men may be subject to. Generally, opportunities for people to be "physically active" exist in four major domains of their day-to-day lives: at work (especially if the job involves manual labor); for transport (e.g., walking or cycling to work); in domestic duties (e.g., housework or gathering fuel); or in leisure time (e.g., participating in sports or recreational activities). In this work, physical inactivity may could have been envisioned as doing very little or no PA in any of these domains. However, two concerns with this regard have been raised. First, an absence of an internationally agreed definition or measure of PA; second, this study only estimates the prevalence of physical inactivity among people aged 18 years and over, many of whom have not joined their workforce yet or did not share any occupational or transport-work experience. As such, most of the desired study data were focused to address leisure-time activity, with fewer, if any, direct data available on occupational activity or for activity relating to transport. Therefore, in order to delineate what is "physical activity" and what is "physical inactivity" for the purpose of this study, certain criteria could be adapted from the guidelines provided by the Centers for Diseases Control and Prevention (CDC) on "general physical activities" (Ainsworth et al., 1993). The guidelines endorse "level of intensity" of exercise as a background for the amount and nature of expend PA. Accordingly, our physical activity outcome variable was outlined as follows:

a) Moderate physical activity: this was determined according to the presence of 3.0 to 6.0 MET (Metabolic Equivalent of Task) that is equivalent to 3.5 to $7.0 \mathrm{kcal} / \mathrm{min}$. In practice, this measurement could be achieved, e.g., by walking at a moderate or brisk pace of 3 to $4.5 \mathrm{mph}$ on a level surface inside or outside, such as walking to class, walking for pleasure; walking the dog; or walking as a break from work. It could also be achieved through walking downstairs or down a hill; or in a "race-walking" pattern in a speed less than $5 \mathrm{mph}$.

b) Vigorous physical activity: This was determined according to the presence of 6.0 or more MET (=more than $7.0 \mathrm{kcal} / \mathrm{min}$ ). In practice, this measurement could be achieved through either "race-walking" or aerobic walking, 5 mph or faster; jogging or running; walking and climbing briskly up a hill; backpacking; or rappelling.

c) Mild physical activity: This lowers activity subcategory involves exercise or physical activity with any level of intensity less than those described in moderate PA. This pattern is generally met with in any activities for less than 30 minutes for 4 days or less per week. In this research, mild physical activity may be indistinguishable from physical inactivity, the negative aspect of the outcome variable of this work. For instance, a subject, e.g., with or without any chronic or behavioral derangement who reports tendency for lower PA may well be considered as equivalent to being physically inactive.

A pilot administration had first been conducted; test-retest reliability calculated to assess the temporal stability of the utilized questionnaire items. Reliability alpha ranging between 0.79 and 0.89 was recorded. Upon completion of the questionnaire, each participant was invited to a clinical interview, medical record thoroughly examined, and then a clinical examination was carried out, including vital signs, visual acuity, and full systemic examination. Participants' medical records were reviewed thoroughly, including previous and medical history, health status incidences, clinical findings, chronic diseases status, and laboratory profiles. The clinical interview data were compared with medical record findings, and an ultimate evaluation of the previous and current health 
status labeling for each participant was reached as being described in this study. The collected data were tabulated and analyzed using the Statistical Package for Social Science (SPSS) version 20. Frequency statistics, e.g., to describe interval- or ratio-scale data, such as age would be calculated using mean and standard deviation, considering normality distribution. Categorical variables were expressed in count and percentage. The social and demographic characteristics would be identified and displayed to describe the socioeconomic status of the study group. Measuring the association between a risk variable of a categorical nature and the study outcome "PA" among the study group, chi-square test of independence, or Fisher's exact tests, where appropriate, would be used. According to the study design, as above, only the relationship between risk factors relevant to chronic morbidity or unfavorable behaviors (e.g., smoking and drug dependence) were to analyze to measure their role in shaping the physical activity profile of the study population. The same trend may not be advocated with the socio-economic status, and only descriptive statistics would be conducted. First, all our subjects are healthcare seekers, most of who may have been suffering one or more of the chronic diseases and or the behavioral problems under evaluation. In which case, measuring the influence of socioeconomic factors upon PA would be confounded by the presence of such ailments, jeopardizing our finding's generalizability potential. Our alpha error $(\alpha)$ to tolerate type-I error was 0.05 , and results with $p$-value less than alpha would be considered significant.

\section{Results}

Socio-demographic characteristics: Table 1 provides description of the socio-demographic traits of the studied population. The vast majority of participants were single (96.0\%). With respect to occupation, $50.6 \%$ of the study sample were recent graduates, most were looking for a job or expecting one), while the manual work mounted $45 \%$, and the unemployed (but not recently graduated) were only $4.4 \%$.

Overall, about two thirds (66.4\%) of the study group belong to middle socioeconomic class, $27.6 \%$ were low socioeconomic-class subjects, and the rest (6\%) were of the highest class (Table 1). As regards education, our study's young men were mostly $(69.8 \%) \geq$ K9-educated $(52.2 \%$ university graduates plus $17.6 \%$ secondary school graduates). The $\leq \mathrm{K}$-9-education group accounted up to 151 (30.2\%) subjects (10.8\% opted out of school while after K-9, 10.6\% had <K-9 education (elementary to intermediate school or can read and write, and 8.8\% are illiterate).

Table 1. Socio-demographic characteristics of the studied population.

\begin{tabular}{|c|c|c|}
\hline \multicolumn{3}{|l|}{ Characteristic } \\
\hline \multirow{2}{*}{$\begin{array}{c}\text { Age (mean } \pm \text { SD) } \\
\text { Marital status }\end{array}$} & \multicolumn{2}{|c|}{$22.46 \pm 2.44$} \\
\hline & No. & $\%$ \\
\hline Single & 480 & 96.0 \\
\hline Married & 20 & 4.0 \\
\hline \multicolumn{3}{|l|}{ Occupation } \\
\hline Recent graduate & 253 & 50.6 \\
\hline Manual work & 225 & 45.0 \\
\hline Jobless & 22 & 4.4 \\
\hline \multicolumn{3}{|l|}{ Social class } \\
\hline High & 30 & 6.0 \\
\hline Middle & 332 & 66.4 \\
\hline Low & 138 & 27.6 \\
\hline \multicolumn{3}{|l|}{ Educational level } \\
\hline$>9$ years & 349 & 69.8 \\
\hline$\leq 9$ years & 151 & 30.2 \\
\hline
\end{tabular}


Risk factors analysis findings: Table 2 represents the impacts of social characteristics on physical activities of studied young adults. Significant association was demonstrated between smoking and diminished physical activity, $58.0 \%$ of smokers were physically inactive, $41.2 \%$ were moderately active, and only $0.8 \%$ were doing vigorous activity $\left[X^{2}(\mathrm{df}=2)=15.53, p<0.001\right]$.

Further, the more the number of smoked cigarettes per day the lower level of PA smokers tend to engage in [Fisher's exact $=28.9, p<0.001$ ] (Table 3). Most of young adults with history of drug abuse or alcohol intake had also low PA $\left[X^{2}(\mathrm{df}=2)=13.96, p<0.001\right.$, Fisher's exact $=6.3, p=0.045$, respectively $]$.

Table 4 displays the distribution of physical activity as by the medical problems of the study's interest. Out of total 31 obese men, 27 (87.1\%) tend to do mild PA, compared to only 4 (12.9\%) obese who performed moderate PA $\left[X^{2}(\mathrm{df}=2)=16.62, p<0.001\right]$. Twenty nine individuals were found with anemia, $68.9 \%$ of whom had mild $\mathrm{PA}, 31 \%$ tended to do moderate $\mathrm{PA}$, and none were engaged in vigorous exercise $\left[X^{2}(\mathrm{df}=2)=8.22, p=0.027\right]$. Similar pattern of PA has been recorded among subjects with CHD, for none were engaged but in mild PA $\left[X^{2}(\mathrm{df}=2)=15.6, p<0.001\right]$ (Table 4).

Nineteen out of our study group were reported with bronchial asthma. The majority (78.9\%) of asthmatics were physically inactive and only (21.1\%) were able to perform moderate exercise; no asthmatics were among the vigorous exercise category $\left[X^{2}(\mathrm{df}=2)=20.65, p<0.001\right]$.

Only 3 of our study group were reportedly epileptics, and all were physically inactive, [Fisher's exact $6.3 p<$ 0.045]. No significant association has been found between physical inactivity and HBV or HCV infections, as well as DM.

Table 2. Distribution of the study group by behavioral traits; and their impact upon physical activity.

\begin{tabular}{|c|c|c|c|c|c|c|c|}
\hline \multirow{2}{*}{$\begin{array}{l}\text { Behavioral trait } \\
\text { (not exclusive) }\end{array}$} & \multicolumn{2}{|c|}{$\begin{array}{l}\text { Mild activity } \\
(\mathbf{n}=220)\end{array}$} & \multicolumn{2}{|c|}{$\begin{array}{l}\text { Moderate activity } \\
\quad(\mathrm{n}=259)\end{array}$} & \multicolumn{2}{|c|}{$\begin{array}{c}\text { Vigorous activity } \\
(\mathrm{n}=21)\end{array}$} & \multirow{2}{*}{ Test statistic p-value } \\
\hline & No. & $\%$ & No. & $\%$ & No. & $\%$ & \\
\hline Smoking $(\mathrm{n}=131)$ & $76 / 131$ & 58.0 & $54 / 131$ & 41.2 & $1 / / 131$ & 0.8 & \multirow{3}{*}{$X^{2}(\mathrm{df}=2)=15.53 p<0.001$} \\
\hline Non-smoking $(\mathrm{n}=369)$ & $\underline{144^{*}}$ & 65.4 & $\underline{205}^{\dagger}$ & 79.1 & $\underline{20}^{\ddagger}$ & 95.2 & \\
\hline Total $(\mathrm{n}=500)$ & 220 & 44.0 & 259 & 51.8 & 21 & 4.2 & \\
\hline Drug abuse $(n=14)$ & $13 / 14$ & 92.9 & $1 / 14$ & 7.1 & $0 / 14$ & 0.0 & \multirow{3}{*}{$X^{2}(\mathrm{df}=2)=13.96 p<0.001$} \\
\hline No Drug abuse (486) & $\underline{207^{*}}$ & 94.1 & $\underline{258}^{\dagger}$ & 99.6 & $\underline{21}^{\ddagger}$ & 100.0 & \\
\hline Total $(\mathrm{n}=500)$ & 220 & 44.0 & 259 & 51.8 & $\frac{21}{21}$ & 4.2 & \\
\hline Alcohol $(\mathrm{n}=5)$ & $5 / 5$ & 100.0 & $0 / 5$ & 0.0 & $0 / 5$ & 0.0 & \multirow{3}{*}{ Fisher's exact $=6.3 p<0.045$} \\
\hline Non alcoholic $(n=495)$ & $\underline{215^{*}}$ & 97.7 & $259^{\dagger}$ & 100.0 & $21^{\ddagger}$ & 100.0 & \\
\hline Total $(n=500)$ & 220 & 44.0 & 259 & 51.8 & 21 & 4.2 & \\
\hline
\end{tabular}

${ }^{*}$ Reference category Mild activity = 220; ${ }^{\dagger}$ Reference category Moderate activity = 259; ${ }^{\ddagger}$ Reference category Vigorous activity = 21.

Table 3. Distribution of smokers by level of PA: dose-response effect.

\begin{tabular}{|c|c|c|c|c|c|c|c|}
\hline \multirow[t]{2}{*}{ Smoking category } & $\begin{array}{l}\text { Mild activity } \\
\quad(n=76)\end{array}$ & $\begin{array}{l}\text { Moderate activity } \\
\qquad(\mathrm{n}=56)\end{array}$ & $\begin{array}{l}\text { Vigorous activity } \\
(n=1)\end{array}$ & \multirow[t]{2}{*}{ Total } & \multirow{2}{*}{$\begin{array}{c}\text { \% of } \\
\text { Smoking }\end{array}$} & \multirow{2}{*}{$\begin{array}{l}\text { \% of } \\
\text { Total }\end{array}$} & \multirow{2}{*}{$\begin{array}{c}\text { Test statistic } \\
\text { p-value }\end{array}$} \\
\hline & No. (\%) & No. (\%) & No. (\%) & & & & \\
\hline $\begin{array}{l}\text { Light (1 - } 10 \text { cigs/d) } \\
\text { (\% Light smoker) }\end{array}$ & $\begin{array}{c}8 \\
(23.5)\end{array}$ & $\begin{array}{c}25 \\
(73.5)\end{array}$ & $1(2.9)$ & $\begin{array}{c}34 \\
(100)\end{array}$ & 25.9 & 6.8 & \\
\hline $\begin{array}{l}\text { Moderate (11 - } 20 \text { cigs/d) } \\
\text { (\% Moderate smoker) }\end{array}$ & $\begin{array}{c}34 \\
(60.7)\end{array}$ & $\begin{array}{c}22 \\
(39.2)\end{array}$ & $0(0.0)$ & $\begin{array}{c}56 \\
(100)\end{array}$ & 42.7 & 11.2 & $\begin{array}{c}\text { Fisher's exact }=28.9 \\
p<0.001\end{array}$ \\
\hline $\begin{array}{l}\text { Heavy (21 - } 39 \text { cigs/d) } \\
\text { (\%Heavy smoker) }\end{array}$ & $\begin{array}{c}34 \\
(82.9)\end{array}$ & $\begin{array}{c}7 \\
(7.1)\end{array}$ & $0(0.0)$ & $\begin{array}{c}41 \\
(100)\end{array}$ & 31.4 & 8.2 & \\
\hline $\begin{array}{c}\text { SUM } \\
\text { (\% Smoker) }\end{array}$ & $\begin{array}{c}76 \\
(58.0)\end{array}$ & $\begin{array}{c}54 \\
(41.2)\end{array}$ & $1(0.7)$ & $\begin{array}{c}131 \\
(100)\end{array}$ & 100 & 26.2 & \\
\hline
\end{tabular}

${ }^{*}$ Only 1participant reported smoking 40 - 50 cigs/d, thereby was included with the heavy smoking group. 
Table 4. Distribution of the study group by medical problems, and their impact upon physical activity.

\begin{tabular}{|c|c|c|c|c|c|c|c|}
\hline \multirow{2}{*}{$\begin{array}{l}\text { Medical problem } \\
\text { (not exclusive) }\end{array}$} & \multicolumn{2}{|c|}{$\begin{array}{l}\text { Mild activity } \\
(\mathrm{n}=220)\end{array}$} & \multicolumn{2}{|c|}{$\begin{array}{l}\text { Moderate activity } \\
\quad(\mathrm{n}=259)\end{array}$} & \multicolumn{2}{|c|}{$\begin{array}{l}\text { Vigorous activity } \\
(\mathrm{n}=21)\end{array}$} & \multirow{2}{*}{ Test statistic p-value } \\
\hline & No. & $\%$ & No. & $\%$ & No. & $\%$ & \\
\hline Obesity $(\mathrm{n}=31)$ & $27 / 31$ & 87.1 & $4 / 31$ & 12.9 & $0 / 31$ & 0.0 & \multirow[b]{2}{*}{$X^{2}(\mathrm{df}=2)=16.62 p<0.001$} \\
\hline $\begin{array}{c}\text { No obesity }(\mathrm{n}=469) \\
\text { Total }(\mathrm{n}=500)\end{array}$ & ${\frac{193^{*}}{220}}^{*}$ & $\begin{array}{l}87.7 \\
44.0\end{array}$ & $\frac{255^{\dagger}}{259}$ & $\begin{array}{l}98.4 \\
51.8\end{array}$ & $\frac{21^{\ddagger}}{21}$ & $\begin{array}{c}100.0 \\
4.2\end{array}$ & \\
\hline Anemia $(n=29)$ & $20 / 29$ & 68.9 & $9 / 29$ & 31.0 & $0 / 29$ & 0.0 & \multirow[b]{2}{*}{$X^{2}(\mathrm{df}=2)=8.22 p=0.027$} \\
\hline $\begin{array}{l}\text { No anemia }(\mathrm{n}=471) \\
\text { Total }(\mathrm{n}=500)\end{array}$ & $\frac{200^{*}}{220}$ & $\begin{array}{l}90.9 \\
44.0\end{array}$ & $\frac{250^{\dagger}}{259}$ & $\begin{array}{l}96.5 \\
51.8\end{array}$ & $\frac{21^{\ddagger}}{21}$ & $\begin{array}{c}10.0 \\
4.2\end{array}$ & \\
\hline $\mathrm{DM}(\mathrm{n}=4)$ & $3 / 4$ & 75.0 & $1 / 4$ & 25.0 & $0 / 4$ & 0.0 & \multirow[b]{2}{*}{$X^{2}(\mathrm{df}=2)=1.61 p=0.193$} \\
\hline No DM $(n=496)$ & $\frac{217^{*}}{220}$ & $\begin{array}{l}98.6 \\
44.0\end{array}$ & $\frac{258^{\dagger}}{259}$ & $\begin{array}{l}99.6 \\
51.8\end{array}$ & $\frac{21^{\ddagger}}{21}$ & $\begin{array}{c}100.0 \\
44.0\end{array}$ & \\
\hline CHD $(n=12)$ & $12 / 12$ & 100.0 & $0 / 12$ & 0.0 & $0 / 12$ & 0.0 & \multirow[b]{2}{*}{$X^{2}(\mathrm{df}=2)=15.65 p<0.001$} \\
\hline $\begin{array}{l}\text { No CHD }(\mathrm{n}=488 \\
\text { Total }(\mathrm{n}=500)\end{array}$ & $\begin{array}{l}208^{*} \\
220\end{array}$ & $\begin{array}{l}94.5 \\
44.0\end{array}$ & $\frac{259^{\dagger}}{259}$ & $\begin{array}{c}100.0 \\
51.8\end{array}$ & $\frac{21^{\ddagger}}{21}$ & $\begin{array}{c}100.0 \\
4.2\end{array}$ & \\
\hline $\mathrm{BA}(\mathrm{n}=19)$ & $15 / 19$ & 78.9 & $4 / 19$ & 21.1 & $0 / 19$ & 0.0 & \multirow[b]{2}{*}{$X^{2}(\mathrm{df}=2)=20.65 p<0.001$} \\
\hline $\begin{array}{l}\text { No BA }(\mathrm{n}=481) \\
\text { Total }(\mathrm{n}=500)\end{array}$ & $\frac{205^{*}}{220}$ & $\begin{array}{l}93.2 \\
44.0\end{array}$ & $\frac{240^{\dagger}}{259}$ & $\begin{array}{l}92.7 \\
51.8\end{array}$ & $\frac{21^{\ddagger}}{21}$ & $\begin{array}{c}100.0 \\
4.2\end{array}$ & \\
\hline Epilepsy $(\mathrm{n}=3)$ & $3 / 3$ & 100.0 & $0 / 3$ & 0.0 & $0 / 3$ & 0.0 & \multirow[b]{2}{*}{ Fisher's exact $=3.84 p<0.001$} \\
\hline $\begin{array}{l}\text { No epilepsy }(\mathrm{n}=497) \\
\text { Total }(\mathrm{n}=500)\end{array}$ & $\frac{217^{*}}{220}$ & 44.0 & ${\frac{256^{\dagger}}{259}}^{\dagger}$ & $\begin{array}{l}98.8 \\
51.8\end{array}$ & $\frac{18^{\ddagger}}{21}$ & $\begin{array}{c}85.7 \\
4.2\end{array}$ & \\
\hline $\begin{array}{c}\operatorname{HBV}(\mathrm{n}=22) \\
\text { No HBV }(\mathrm{n}=478) \\
\text { Total }(\mathrm{n}=500)\end{array}$ & $\begin{array}{c}14 \\
\frac{206}{20}^{*}\end{array}$ & $\begin{array}{l}63.6 \\
93.6 \\
44.0\end{array}$ & $\begin{array}{c}8 \\
\frac{251^{\dagger}}{259}\end{array}$ & $\begin{array}{l}36.4 \\
96.9 \\
51.8\end{array}$ & $\begin{array}{c}0 \\
\underline{21^{\ddagger}} \\
\underline{21}\end{array}$ & $\begin{array}{c}0.0 \\
100.0 \\
44.0\end{array}$ & $X^{2}(\mathrm{df}=2)=4.04 p=0.237$ \\
\hline $\begin{array}{c}\operatorname{HCV}(\mathrm{n}=56) \\
\text { No HCV }(\mathrm{n}=444) \\
\text { Total }(\mathrm{n}=500)\end{array}$ & $\begin{array}{c}31 \\
\frac{189}{220}^{*}\end{array}$ & $\begin{array}{l}55.3 \\
85.9 \\
44.0\end{array}$ & $\begin{array}{c}24 \\
\frac{235^{\dagger}}{259}\end{array}$ & $\begin{array}{l}42.9 \\
90.7 \\
51.8\end{array}$ & $\begin{array}{c}1 \\
\frac{20^{\ddagger}}{21}\end{array}$ & $\begin{array}{c}1.8 \\
95.2 \\
4.2\end{array}$ & $X^{2}(\mathrm{df}=2)=3.70 p=0.295$ \\
\hline
\end{tabular}

*Reference category Mild activity = 220; ${ }^{\dagger}$ Reference category Moderate activity = 259; ${ }^{\ddagger}$ Reference category Vigorous activity = 21.

\section{Discussion}

The World Health Organization (WHO) considers physical inactivity to be the fourth leading cause of mortality, worldwide (WHO, 2009). A great amount of effort has been made to minimize the impact of sedentary lifestyles on the public health system which is why physical activity was included in the Global Strategy on Diet, Physical Activity and Health, an agenda released by the WHO in 2004 (WHO, 2004), and most recently, in a document published by the American Heart Association (Artinian et al., 2010). Physical activity has long been identified as a key issue related to an individual's health and well-being as well as decreasing the risks of many health disorders e.g., obesity and CHD. In the present work, only $4.2 \%$ of the studied population was involved in different forms of regular vigorous physical activity. In contrast, Felicitas et al. (1999), recorded that $41.6 \%(n=4171)$ young people 15 - 25 practiced vigorous physical activities as a part of their lifestyle. Similarly, Dowda et al. (2003) found that $38.4 \%(n=4152)$ Americans young adults $(18$ - 30 years) share in regular vigorous activities. This difference between the results of these studies and the present work may be attributed to a varied socio-economic and cultural status between the southern area of Egypt, home to this study, and the industrial societies as Felicitas and collaborates'. In the latter, economic resources enabling investing generously in health promotion are abundant. Further, the role of school educational programs, media, and social empowerment, as well as incentives dedicated to maintain a healthier lifestyle, especially PA (and also tobacco prevention), all set the stage for a substantial success in favor of improving the public's health and minimizing chronic disease burden both through promoting PA and combating physical inactivity and sedentary life.

Regarding smoking, Lowry et al. (1996) and others (Suminski et al., 2002; USDHHS, 1996) agree that smoking and physical inactivity are strongly related to a deterioration in overall health status and are among the most 
important modifiable risk factors for chronic disease and premature death (WHO, 2002, 2008). The prevalence of smoking in our study group is $26.2 \%$ (Table 3). Comparably, Lawrence et al. (2007) found that $26 \%$ of young adults were current smokers, $20 \%$ were daily smokers, and $8 \%$ were former smokers. The lower the socioeconomic or educational standard the higher was the rate. In the current work a significant association was demonstrated between smoking and physical inactivity whereas $58.0 \%$ of smokers could not maintain a meaningful PA as a part of their way of living, and only $0.8 \%$ of smokers were able to do so. Although the inverse relationship between smoking and PA and fitness in young adults has been documented, such association has been somewhat in consistent (Conway \& Cronan, 1992), e.g., compared to smoking and PA research in adults (Kaczynski et al., 2008). Moreover, fewer studies have examined the interrelation between smoking volume and PA in young smokers. To this end, we could emphasize that smoking volume was in general significantly inversely associated with PA. A significant dose-response relationship between levels of smoking and physical in activity has been found in our work. In their attempt to identify the relationship between PA and type of smoking behavior among adolescents and young adults, Charilaou et al. (2009) found a consistently negative relationship between PA and smoking among studied Cypriot young adults. The greater the intensity of youths' physical activity, the less likely they were to smoke. Compared with inactive individuals, physically active ones smoked fewer cigarettes and were more likely to be nonsmokers or occasional smokers (Charilaou et al., 2009). As in smoking, most of young adults with history of drug abuse or alcohol intake had also low PA levels. In comparison, a similar trend regarding limited PA attitude and substance abuse or alcohol intake has been recorded elsewhere (Sallis et al., 2000).

More than $87 \%$ of obese individuals and all epileptics had mild PA; also did all those with heart diseases. Physical inactivity and obesity are modifiable risk factors for many chronic diseases, including cardiovascular disease, DM, osteoporosis, osteoarthritis, and depression. Both physical inactivity and obesity are associated with low-grade systemic inflammation that may contribute to the inflammatory processes present in many chronic diseases (Blair et al., 2013; Donnelly et al., 2009; Church et al., 2011). There are epidemiological data in agreement with our finings concerning the relationship between epilepsy and physical exercise in various countries. Bjorholt et al. (1990) observed that patients with epilepsy from a Norwegian population were half as active physically as the normal population, and their physical fitness corresponded to their sedentary lifestyle. Other studies confirmed these findings showing that people with epilepsy have a low degree of participation in physical activities (Nakken, 1999; Roth et al., 1994). More recently, analyzing physical exercise habit in Brazilian patients with epilepsy, it was observed that most of patients did not regularly engage in physical activity (Arida et al., 2003). Likewise, most of anemics or those with bronchial asthma were physically inactive (had mild PA), and some had moderate PA. Some international studies also report comparable results (USDHHS, 1996; WHO, 2002).

Overall, the present study reveals that PA largely tends to be abandoned in subjects with some chronic illnesses, such as CHD, BA, epilepsy, and also in those who embrace risk behavior that may well incapacitate the person's physical fitness as well as mental performance, particularly smoking or drug dependence. On the other hand, PA was not significantly influenced by other chronic diseases, such as HBV, HCV infection, and DM. The notion that some chronic health problems do not intimidate Egyptians to opt a physically inactive life is notably met with in similar studies from different geographical areas of the world (USDHHS, 1996; WHO, 2002; Kaczynski et al., 2008; Jamal et al., 1999). This particular finding could be invested in any contemplated youth behavior and PA promotion programs. While the Egyptian young population's attitude to PA did not live up to that of some of the developed-world peers' when unfavorable socioeconomic circumstances was to intervene, they unsurprisingly share peers a positive perspective to PA in the presence of some commonly prevalent chronic diseases, i.e., viral hepatitis and diabetes mellitus.

Actually, there has been a large body of evidence on the favorable health effects of PA for adults, which is also well accepted by the majority of health professionals. However, the benefits of PA in youth and young adults were still less well documented. Yes some reviewers have identified few modest positive effects in subsamples of youth on such health outcomes as aerobic fitness, blood lipids, blood pressure, glucose metabolism, skeletal health, and psychological health (James et al., 2000). And some have issued guidelines specifically for youth PA, but there still is a debate over the amount and types of activity needed for health benefits. Some recommendations tend to encourage young people to accumulate 30 to 60 minutes per day (min/d) ranging up to several hours/d. Although about $80 \%$ of adolescents are estimated to spend at least $30 \mathrm{~min} / \mathrm{d}$ being active, probably less than half are active at least $60 \mathrm{~min} / \mathrm{d}$ (James et al., 2000). In essence, PA has important health benefits in youth and many young people are not meeting established guidelines, thereby improving PA levels of youth 
is an important public health challenge. To develop effective PA interventions for the youth, influences and determinants of activity levels needed to be understood. As above, the reviews of the correlates of youth PA are not comprehensive, relied on narrative evaluations of the literature, and restricted either the age of young people or the categories of variables included in the reviews. Using self-report measures to study physical inactivity pattern expectedly reveals more PA than those using objective measures. Further, little, if any, reviews or research have been undertaken on the Egyptian youth. The present work bridges the gap in knowledge in the pattern and determinants of physical inactivity among young adult Egyptians, a sector which constitutes a significant proportion of the population block of this nation.

Importantly, this work could quantify the physical inactivity correlates that when disseminated to the public health community a better understanding and planning for improving youth health could be achieved helping them lead a physically active life and a preventive behavior. With this respect, there should be an emphasis on interventions directed to most influential identified correlates of physical inactivity risks, especially smoking, obesity. We learn from the experience with this research that sustained moderate PA and above has been associated with specific health benefits, therefore this pattern of activity is highly recommended in maintaining and improving our youth health standard.

\section{Conclusion}

In conclusion, this work presents some quantitative and measurable information about the physical activity question in Egypt. Although the study sample was satisfactorily representative of the studied population, the geographical coverage could not completely expand beyond the studied district, mostly due to the financial and resource limitations. However, the submitted body of information may well be utilization for developing a comprehensive, and perhaps a population-based physical activity behavior change plan. In the pursuit to improve the physical activity behavior of the Egyptian populations, further research advocating a larger-scale self-reporting measures and cross-sectional surveillance, such as the one in hand, would rather be contemplated. In which case, a clearer picture of PA situation among young adults may be obtained. As such, determinants and risk factors, whether behavioral, morbidity-related, socioeconomic or demographic, all could be depicted. Afterwards, setting a cost-effective remedial plan to bolster the physical activity movement among Egyptian youth would be fruitful, bringing about the most desirable health and societal outcomes. Tactically, an emphasis should also be placed on the preventive and therapeutic services, such as: a) screening for early detection and treatment of anemia; b) improving clinical care and health education of asthmatic youth; and c) assessment of risk associated with CHD in the youth periodically and consistently. Risks of CHD, BA, anemia, and other risks which lead to addiction, tobacco use, and obesity, all are modifiable, the addressing of which in prevention plans should be more effective in changing youth health behavior.

\section{References}

ADA (American Diabetes Association) (2011). Standards of Medical Care in Diabetes—2011. Criteria for the Diagnosis of Diabetes. http://care.diabetesjournals.org/content/34/Supplement_1/S11.full.pdf+html

Afifi, R., \& Omar, S. A. (2012). A Community Screening Plan for the Prevalence of Some Chronic Diseases in Specified Adult Populations: Pre-Diabetes and Diabetes Mellitus. International Journal of Diabetes in Developing Countries, 35, 149-156. http://link.springer.com/article/10.1007/s13410-013-0189-0

AHA (American Heart Association). Coronary Artery Disease-Coronary Heart Disease. http://www.heart.org/HEARTORG/Conditions/More/MyHeartandStrokeNews/Coronary-Artery-Disease---Coronary-Heart -Disease_UCM_436416_Article.jsp

Ainsworth, B. E., Haskell, W. L., \& Leon, A. S. (1993). Compendium of Physical Activities: Classification of Energy Costs of Human Physical Activities. Medicine and Science in Sports and Exercise, 25, 71-80. http://dx.doi.org/10.1249/00005768-199301000-00011

Arida, R. M., Scorza, F. A., de Albuquerque, M., Cysneiros, R. M., de Oliveira, R. J., \& Cavalheiro, E. A. (2003). Evaluation of Physical Exercise Habits in Brazilian Patients with Epilepsy. Epilepsy \& Behavior, 4, 507-510. http://dx.doi.org/10.1016/S1525-5050(03)00184-7

Artinian, N. T., Fletcher, G. F., Mozaffarian, D., Kris Etherton, P., Van Horn L., Lichtenstein, A. H. et al. (2010). Interventions to Promote Physical Activity and Dietary Lifestyle Changes for Cardiovascular Risk Factor Reduction in Adults. A Scientific Statement from the American Heart Association. Circulation, 122, 406-441. http://dx.doi.org/10.1161/CIR.0b013e3181e8edf1 
Bhat, V. M., Cole, J. W., Sorkin, J. D., Wozniak, M. A., Malarcher, A. M., Giles, W. H., Stern, B. J., \& Kittner, S. J. (2008). Dose-Response Relationship between Cigarette Smoking and Risk of Ischemic Stroke in Young Women. Stroke, 39, 2439-2443. http://dx.doi.org/10.1161/STROKEAHA.107.510073

Bjorholt, P. G., Nakken. K. O., Rohme, K., \& Hansen, H. (1990). Leisure Time Habits and Physical Fitness in Adults with Epilepsy. Epilepsia, 31, 83-87. http://dx.doi.org/10.1111/j.1528-1157.1990.tb05364.x

Blair, S. N., Archer, E., \& Hand, G. A. (2013). Luke and Cooper Are Wrong: Physical Activity Has a Crucial Role in Weight Management and Determinants of Obesity. Int J Epidemiol, 43, 1836-1838. http://dx.doi.org/10.1093/ije/dyt160

Blair, S. N., Kohl, R. S., Paffenbarger, D. G., Clark, K. H., \& Gibbons, L. W. (1989). Physical Fitness and All-Cause Mortality. JAMA, 262, 2395-2401. http://dx.doi.org/10.1001/jama.1989.03430170057028

CAPMS (Central Agency for Public Mobilization and Statistics) (2012) Population. Arabic Republic of Egypt. http://www.sis.gov.eg/En/Templates/Articles/tmpArticles.aspx?ArtID=9\#.VTX-RCGqqko

CDC (Centers for Disease Control and Prevention) (1997). Guidelines for School and Community Programs to Promote Lifelong Physical Activity among Young People. MMWR, 46, 1-36.

CDC (Centers for Disease Control and Prevention) (2014). Division of Viral Hepatitis. What Is Hepatitis B? http://www.cdc.gov/hepatitis/HBV/PDFs/HepBGeneralFactSheet.pdf

Charilaou, M., Karekla, M., Constantinou, M., \& Price, S. (2009). Relationship between Physical Activity and Type of Smoking Behavior among Adolescents and Young Adults in Cyprus. Nicotine \& Tobacco Research, 11, 969-976. http://dx.doi.org/10.1093/ntr/ntp096

Church, T. S., Thomas, D. M., Tudor-Locke, C., Katzmarzyk, P. T., Earnest, C. P., Rodarte. R. Q., Martin, C. K., Blair, S. N., \& Bouchard, C. (2011). Trends Over 5 Decades in U.S. Occupation-Related Physical Activity and Their Associations with Obesity. PLOS ONE, 6, e19657. http://dx.doi.org/10.1371/journal.pone.0019657

Conway, T. L., \& Cronan, T. A. (1992). Smoking, Exercise, and Physical Fitness. Preventive Medicine, 21, 723-734. http://dx.doi.org/10.1016/0091-7435(92)90079-W

Donnelly, J. E., Blair, S. N., Jakicic, J. M., Manore, M. M., Rankin, J. W., \& Smith, B. K. (2009). American College of Sports Medicine Position Stand. Appropriate Physical Activity Intervention Strategies for Weight Loss and Prevention of Weight Regain for Adults. Medicine \& Science in Sports \& Exercise, 41, 459-471. http://dx.doi.org/10.1249/MSS.0b013e3181949333

Dowda, M., Ainsworth, B. E., Addy, C. L., Saunders, R., \& Riner, W. (2003). Correlates of Physical Activity among U.S. Young Adults, 18 to 30 Years of Age, from the Third National Health and Nutrition Examination Survey (NHANES III). Annals of Behavioral Medicine, 26, 15-23. http://dx.doi.org/10.1207/S15324796ABM2601_03

EHC (Epilepsy Health Center) (2014). Diagnosing Epilepsy. http://www.webmd.com/epilepsy/guide/diagnosing-epilepsy

Fahmy, S. I., \& El Sherbini, A. F. (1983). Determining Simple Parameters for Social Classification for Health Research. Bulletin of the High Institute of Public Health, 8, 95-107.

Felicitas, D. B., Carme, B., Mabel, N., \& Antoni, P. (1999). Physical Activity Assessment in Population Survey. International Journal of Epidemiology, 28, 53-57. http://dx.doi.org/10.1093/ije/28.1.53

Ferraro, K. F., \& Holland, K. B. (2002). Physician Evaluation of Obesity in Health Surveys. Social Science \& Medicine, 55, 1401-1413. http://dx.doi.org/10.1016/S0277-9536(01)00272-6

Fletcher, G. F., Blair, J., Blumenthal, C., \& Caspersen, B. A. (1992). Statement on Exercise; Benefits and Recommendations for Physical Activity Programs for All Americans. Circulation, 86, 340-344. http://dx.doi.org/10.1161/01.CIR.86.1.340

GSAP (Global Strategy for Asthma Management and Prevention) (2011). http://www.ginasthma.org/uploads/users/files/GINA_Report2011_May4.pdf

Jamal, M. M., Sonni, S., \& Quinn, P. G. (1999). Clinical Features of Hepatitis C-Infected Patients with Persistently Normal Alanine Transferase Levels in the Southwestern United States. Hepatology, 30, 1307-1311. http://dx.doi.org/10.1002/hep.510300526

James, F. S., Prochaska, J., \& Taylor, W. C. (2000). A Review of Correlates of Physical Activity of Children and Adolescents. Medicine and Science in Sports \& Exercise, 32, 963-975.

JUNP-AIDS/HIV (Joint United Nations Program on HIV and AIDS) (UNAIDS/WHO) (2004). Epidemiological Fact Sheet—2004 Update. http://data.unaids.org/publications/fact-sheets01/egypt_en.pdf

Kaczynski, A. T., Manske, S. R., Mannel, R. C., \& Grewal, K. (2008). Smoking and Physical Activity: A Systematic Review. American Journal of Health Behavior, 32, 93-110. http://dx.doi.org/10.5993/AJHB.32.1.9

Klesges, R. C., Hanson, C. K., \& Haddock, L. M. (1990). Effects of Obesity, Social Interactions, and Physical Environment on Physical Activity in Preschoolers. Health Psychology, 9, 435-449. http://dx.doi.org/10.1037/0278-6133.9.4.435

Kolbe, L. J. (1990). An Epidemiological Surveillance System to Monitor the Prevalence of Youth Behaviors That Most Affect Health. Health Education, 21, 44-48. 
Lawrence, D., Fagan, P., Backinger, C. L., Gibson, J. T., \& Hartman, A. (2007). Cigarette Smoking Patterns among Young Adults Aged 18-24 Years in the United States. Nicotine \& Tobacco Research, 9, 687-697. http://dx.doi.org/10.1080/14622200701365319

Lowry, R., Collins, J. L., Kann, L., \& Kolbe, J. L. (1996). Effect of Socioeconomic Status on Chronic Disease Risk Behavior among US Adolescents. JAMA, 276, 792-797. http://dx.doi.org/10.1001/jama.1996.03540100036025

Moore, L. L., Lombardi, M. J., White, J. L., Campbell, S. A., Oliveria, P., \& Ellison, R. C. (1991). Influence of Parents' Physical Activity Levels on Activity Levels of Young Children. The Journal of Pediatrics, 118, 215-219. http://dx.doi.org/10.1016/S0022-3476(05)80485-8

Nakken, K. O. (1999). Physical Exercise in Outpatients with Epilepsy. Epilepsia, 40, 643-651. http://dx.doi.org/10.1111/j.1528-1157.1999.tb05568.x

NHLBI (National Heart, Lung, and Blood Institute) (2013). What Is Coronary Heart Disease? Bethesda, MD: National Institute of Health, DHHS. http://www.nhlbi.nih.gov/health/health-topics/topics/cad

Pate, R. M., Pratt, S. N., Blair, W. L, \& Haskell, T. L. (1995). Physical Activity and Public Health. JAMA, 273, $402-407$. http://dx.doi.org/10.1001/jama.1995.03520290054029

Raitakari, O. T., Porkka, S., Taimela, R., Telama, L., Rasanen, O. P., Viikari, J. et al. (1994). Effects of Persistent Physical Activity and Inactivity on Coronary Risk Factors in Children and Young Adults. American Journal of Epidemiology, 140, 195-205.

Roth, D. L., Goode, K. T., Williams, V. L., \& Faught, E. (1994). Physical Exercise, Stressful Life Experience, and Depression in Adults with Epilepsy. Epilepsia, 35, 1248-1255. http://dx.doi.org/10.1111/j.1528-1157.1994.tb01796.x

Sallis, J. F., Prochaska, J. J., \& Taylor, W. C. (2000). A Review of Correlates of Physical Activity of Children and Adolescents. Medicine \& Science in Sports \& Exercise, 32, 963-975. http://dx.doi.org/10.1097/00005768-200005000-00014

Salmon, K. J. (2000). Leisure-Time, Occupational and Household Physical Activity among Professional, Skilled and LessSkilled Workers and Homemakers. Preventive Medicine, 30, 191-199. http://dx.doi.org/10.1006/pmed.1999.0619

Siegel, M., Mowery, P. D., \& Strauss, W. J. (2000). Trends in Adult Cigarette Smoking in California Compared with the Rest of the United States, 1978-1994. American Journal of Public Health, 90, 372-379. http://dx.doi.org/10.2105/AJPH.90.3.372

Suminski, R. R., Petosa, R., Utter, A. C., \& Zhang, J. J. (2002). Physical Activity among Ethnically Diverse College Students. Journal of American College Health, 51, 75-80. http://dx.doi.org/10.1080/07448480209596333

USDHHS (U. S. Department of Health and Human Services) (1996). Physical Activity and Health: A Report of the Surgeon General. Washington DC: USDHHS.

Washburn, R. A., \& Montoye, H. J. (1986). The Assessment of Physical Activity by Questionnaire. American Journal of Epidemiology, 123, 563-575.

WHO (World Health Organization) (2002). World Health Report on Reducing Risks and Promoting Healthy Life. Geneva: World Health Organization. http://www.who.int/whr/2002/en/whr02_en.pdf

WHO (World Health Organization) (2004). Global Strategy on Diet, Physical Activity and Health. Geneva: World Health Organization.

WHO (World Health Organization) (2008). Report on the Global Tobacco Epidemic. Geneva: World Health Organization. http://www.who.int/tobacco/mpower/2008/en/

WHO (World Health Organization) (2009). Global Health Risks: Mortality and Burden of Disease Attributable to Selected Major Risks. Geneva: World Health Organization.

Zaytoun, S., Afifi, R., Alsenbesy, M., \& Ayoub, H. (2015). Patterns and Distribution of Drug Dependence and Associated Risk Factors among Male Youth in Upper Egypt. European Journal of Scientific Research, 131, 215-219. 